\title{
La contribución de las geografías personales en la comunicación estratégica del territorio*
}

\author{
Jordi de San Eugenio Vela' \\ Universidad de Vic - Universitat Central de Catalunya (España)
}

Recibido: agosto 2 de 2014 - Revisado: noviembre 6 de 2014 - Aceptado: diciembre 10 de 2014

Referencia formato APA: San Eugenio-Vela, J. (2014). La contribución de las geografías personales en la comunicación estratégica del territorio. Revista Cientifica Guillermo de Ockham, 12(2), 11-24.

\section{Resumen}

A menudo se habla del sesgo perceptivo entre la imagen emitida (cómo queremos que nos vean) y la imagen percibida (cómo realmente nos ven). En este sentido, el artículo pretende mostrar las contribuciones teóricas de la geografía subjetiva (de la percepción, humanística y emocional) en el proceso de correlación existente entre la imagen de un destino turístico comunicada o evocada a priori y la experiencia con el lugar percibida in situ. El equilibrio existente entre la "promesa inicial" y la "experiencia final" con el espacio turístico, resulta ser uno de los aspectos más importantes por considerar en el despliegue de una estrategia de comunicación turística. La introspección hacia las "geografías de la vivencia personal" pretende explorar la experiencia individual con el lugar desde un punto de vista perceptivo y emocional.

Palabras clave: Espacio turístico, comunicación, territorio, percepción, emoción

\section{The contribution of personal geographies in the strategic communication of places}

\section{Abstract}

We often talk about the perceptual bias between emitted image (how we want to see us) and projected image (how we really see us). In this sense, this article shows the theoretical contributions from the personal geographies tradition (perception, humanism and emotion) in the correlation process between the image of a tourist destination communicated a priori and the experience with place perceived in situ. The balance between the 'initial promise' and the 'final experience' with the touristic space is one of the most important issues to consider in the tourism communication strategy. The paper proposes a theoretical research of 'geographies of personal experience' to explore the individual experience with places from an emotionally perspective.

Keywords: Touristic space, communication, territory, perception, emotion

* Este artículo incorpora parte de los resultados de investigación de la tesis doctoral La transformación de territorios en marcas: el reconocimiento y la diferenciación de identidades espaciales en tiempos posmodernos. Un estado de la cuestión, dirigida por el doctor Joan Nogué y la doctora Mònika Jiménez.

1. Doctor con Premio Extraordinario de Doctorado en Comunicación Social por la Universitat Pompeu Fabra. Vicedecano para la investigación, la calidad docente y la transferencia de conocimiento de la Facultad de Empresa y Comunicación de la Universitat de Vic-Universitat Central de Catalunya. Ha sido director del Departamento de Comunicación de la misma universidad (2011-2013) del cual forma parte actualmente como profesor. Colabora con el Departamento de Geografía y con la Facultad de Turismo de la Universitat de Girona. Tutor de los estudios de turismo de la Universidad Oberta de Catalunya y consultor del máster oficial de la Organización Mundial del Turismo. E-mail: jordi.saneugenio@uvic.cat 


\section{La geografía de la percepción y del comportamiento ambiental}

La geografía de la percepción se sitúa a medio camino entre las geografías cuantitativas y cualitativas. De hecho, surgió como respuesta a la ineficiencia en cuanto a explicación e interpretación de la realidad geográfica proveniente de los modelos espaciales geográficos, íntimamente vinculados a la geografía más positivista (Capel, 1981). En este contexto, los estudios de percepción y comportamiento humanos pretendían aportar un valor añadido de explicación y predicción de los fenómenos de localización espacial de las actividades llevadas a cabo por la ciudadanía.

El origen de la percepción en geografía, se encuentra vinculado al estudio de los riesgos ambientales con relación al riesgo percibido por la ciudadanía (Gómez Rojas, 2006). Más adelante, la percepción en geografía se trasladó desde los estudios de la vulnerabilidad humana al análisis del espacio urbano o metropolitano, en el que las aportaciones de Bailly con La percepción del espacio urbano (1979) y Lynch en The Image of the City (1960) resultaron decisivas.

Así, por primera vez se incorporaba el saber psicológico a la ciencia geográfica. En todo caso, la geografía de la percepción y del comportamiento ambiental abrió paso a la interdisciplinariedad-además de ser incluida por algunos autores-en el contexto de la revolución conductista (behavioural revolution). En efecto, la aportación de Lowenthal llamada Geography, Experience and Imagination: Towards a Geographic Epistemology publicada en 1961, vinculó definitivamente el interés geográfico al descubrimiento de las imágenes del entorno, lo que permitió anexar la geografía a la psicología de tradición europea (Estébanez, 1979).

La constitución de un núcleo duro de investigación geográfica vinculado a la percepción del medio y el comportamiento espacial se sitúa en el año 1965, justo cuando tuvo lugar la reunión anual de la Asociación Americana de Geógrafos, de la cual surgió la constitución del grupo de trabajo Percepción y Comportamiento Ambiental, encabezado por Lowenthal. Paralelamente, en 1969 surge el grupo EDRA (Environmental Design Research Association) integrado mayoritariamente por arquitectos y especialistas en diseño ambiental que también se vincularon al estudio de la percepción y al comportamiento ambiental (de Castro, 2005).

En este sentido, la aparición de la obra Image and environment: Cognitive mapping and spatial behavior aparecida en 1973 de la mano de Stea (planificador urbano) y Downs (geógrafo), pone de relieve la rotura de las barreras disciplinarias a las que históricamente se había sometido a la geografía. Así, en esta publicación, aparecen aportaciones disciplinarias provenientes de la psicología, la geografía, la sociología, la antropología y la biología, entre otras.

Asimismo, se incorporaron a la praxis geográfica aspectos como el comportamiento, la información y la decisión, que enlazaban perfectamente con algunos de los aspectos vinculados a la imagen de la ciudad planteados inicialmente por Lynch (1960). En este escenario, la vinculación de la geografía de la percepción con la psicología ambiental se hizo muy evidente, sobre todo en cuanto a la definición de objetos de estudio compartidos, tales como la evaluación y la percepción ambiental, la representación cognitiva de ambientes a gran escala, la conducta espacial humana y las respuestas a un determinado paisaje.

En efecto, la introducción de la variable cognitiva o de la vivencia interna del individuo sacudió algunos de los postulados irrenunciables del pensamiento geográfico, más ocupados de la realidad geográfica externa que de la realidad subjetiva, perceptiva y, por tanto, interna de los individuos. La subjetividad del espacio geográfico, el pensamiento, el sentimiento, la creencia, y, en definitiva, las variables sensoriales, acapararon la atención de la geografía a finales de los años sesenta y comienzos de los setenta del siglo XX.

La experiencia geográfica o la inquietud por determinar de qué manera la sociedad y los individuos ven la tierra donde viven y cómo esta visión condiciona su manera de actuar, determina las coordenadas de investigación geográfica de la época. También son muchos los autores que consideran que la geografía de la percepción y del comportamiento ambiental se convirtió en una primera reacción al molde homogeneizador impuesto por la geografía cuantitativa, hegemónica hasta ese momento (Estébanez, 1979; Capel, 1981; García-Ballesteros, 1986; de Castro, 2005).

La sistematización de la percepción geográfica se vehicula mediante la producción de mapas mentales, los cuales actúan a modo de indicadores de procesos generales de toma de decisiones espaciales de la sociedad (Estébanez, 1979). En el marco de la percepción espacial, también se aborda, entre otras cosas, el estudio de catástrofes naturales (sequías, terremotos, etc.), de condiciones climáticas o físicas del medio, de evaluación de recursos y actitudes ante el entorno, de percepción del paisaje y del paisaje urbano en particular, de imágenes espaciales o bien de la conciencia territorial y regional (Capel, 1981).

$12<$ Universidad de San Buenaventura, Cali - Colombia 
Aparte de una reacción en contra de la definición de modelos normativos y estáticos en geografía, la incorporación de la percepción implica considerar aspectos en geografía nunca antes tenidos en cuenta, como el emergente interés por descubrir el mundo de la experiencia personal vivida con el medioambiente por los individuos, el papel de la imaginación o, en definitiva, el mundo privado experimentado por la humanidad. Asimismo, el inicio de la investigación geográfica vinculada a aspectos de comportamiento ambiental fue llevado a cabo por Kirk en 1952, quien se encargó de presentar el concepto de Gestalt a los geógrafos (Unwin, 1985).

No hay duda de que la percepción del medio proviene de una esfera superior anclada en las generalidades propias de la percepción humana. En este sentido, hay que añadir a la mera percepción otros aspectos vinculados a la existencia humana, como son los elementos temporales, las intuiciones, las relaciones o incluso, los aspectos emocionales. Es por este motivo que la geografía de la percepción se inscribe en una corriente subjetiva de análisis territorial vinculado a una voluntad de entender, desde un punto de vista de comprensión interpretativa, la realidad del individuo ubicado en el espacio a partir de la aportación de la fenomenología o el existencialismo y del pensamiento de autores como Husserl, Heidegger o Schutz, por citar solo algunos ejemplos (García-Ballesteros, 1986).

El trabajo específico con el espacio personal, con el espacio de vida percibido sin mediación, es uno de los focos de investigación más importantes asociados a la geografía de la percepción. Así, la información ambiental pasa por el tamiz de la experiencia personal, anexionada a motivos, intereses y valores de ámbito individual, y acaba representando un ejercicio de subjetivación del medio geográfico (De Castro, 2005).

En este sentido, Gómez Rojas (2006) sostiene que, en términos generales, el punto de partida de todas las teorías sobre la percepción geográfica señala que entre el objeto real y el sujeto que lo capta no existe una comprensión per se, sino que el objeto es transformado por la percepción humana, aunque de este mismo objeto se mantiene una imagen mental mediante la cual el individuo decidirá la conducta que mantendrá en relación al objeto. Es decir, la presentación del objeto no es equivalente a su representación, o dicho de otra manera, la presentación es el significante y la representación es el significado atribuido individualmente al objeto en cuestión. Así las cosas, la información proporcionada por la realidad se ve limitada o bien sometida a los designios de las percepciones, para pos- teriormente sufrir nuevas modificaciones en función del efecto transformador de los órganos sensoriales humanos.

El interés de integración de la geografía de la percepción y del comportamiento ambiental a la propuesta teórica de comunicación del espacio turístico, se encuentra en la posibilidad de relacionar la llamada "imagen-imaginación"; o sea, la concreción de una imagen para un determinado territorio proveniente de una información mediatizada (medios de comunicación, mediante estrategias de mercadeo, branding, etc.), que se produce cuando el sujeto objeto de análisis no ha tenido una experiencia directa y ni siquiera ha visitado el espacio percibido, en consonancia con la imagen percibida en primera persona in situ, como resultado de la interacción individuo-entorno y, por tanto, de la experiencia directa con el espacio geográfico y simbólico.

Así pues, la apuesta por una geografía del espacio vivido, una geografía, en definitiva, cognitiva, implica una apertura a la interdisciplinariedad poco habitual en la praxis geográfica y supone una introspección hacia los mundos percibidos y vividos internamente por el individuo y hacia la identificación de las imágenes que la sociedad se ha formado en relación con el espacio geográfico que la envuelve.

El componente de subjetividad inherente a la geografía de la percepción viene determinado por las reacciones que el individuo experimenta en relación con un determinado entorno, las cuales son facilitadas por una determinada apreciación de los objetos que lo integran más que por las características reales de estos mismos objetos. Así, la preponderancia otorgada a la percepción sensorial se convierte en capital para explicar determinadas reacciones y comportamientos de los individuos ante específicas realidades del espacio geográfico.

La geografía de la percepción presenta dos características singulares en relación con otras corrientes de pensamiento incluidas en la tradición geográfica (De Castro, 2005). Por un lado, la geografía de la percepción es una geografía de la cotidianidad, alejada de una abstracción teórica huidiza de la realidad. Nace, por tanto, de la confrontación del ser humano con el medioambiente que lo rodea. Por otra parte, se constituye a partir de una clara vocación práctica; esto es, una geografía de servicio a la comunidad, con fines prácticos o aplicados, alejada de la rigidez académica. La geografía de la percepción y del comportamiento ambiental es, pues, una geografía personal, subjetiva, sensorial y cognitiva. 


\section{La geografía humanística}

La geografía humanística representa la respuesta más clara al rechazo sistematizado a la geografía cuantitativa de raíz positivista, caracterizada por la definición de modelos espaciales de naturaleza matemática y para el estudio geométrico del espacio geográfico (Capel, 1981; Estébanez, 1982; García-Ballesteros, 1986; Unwin, 1995; Ortega-Valcárcel, 2000).

En este sentido, la geografía humanística se inspira en la aportación de la fenomenología existencial y del idealismo, pero también en el pragmatismo y el realismo, los cuales, en su conjunto, proclaman la riqueza de la existencia humana (Estébanez, 1982; Unwin, 1995). Según el geógrafo Tuan (1976), el humanismo en geografía debe ocuparse de la reflexión en torno a los fenómenos geográficos, con el objetivo de conseguir una mejor comprensión de los individuos y de su condición.

La geografía humanística dispone de tres características principales que la singularizan en relación con el resto de corrientes de pensamiento inscritas en la tradición geográfica (Unwin, 1995). En primer lugar, se trata de una crítica abierta y directa a la geografía basada en el positivismo lógico; en segundo lugar, pretende un acercamiento a la complejidad inherente a la subjetividad humana; finalmente, busca la priorización de la comprensión y la reflexión por delante de la explicación. Por todo ello, la geografía humanística se encuentra muy próxima a los dictados de las ciencias históricas y hermenéuticas.

En efecto, la entrada en escena de los pensamientos, los sentimientos y de las intuiciones provoca la mutación de una concepción inicial a modo de espacio geométrico hacia una nueva concepción del entorno entendido como espacio emocional, con una carga simbólica propia que impulsa una nueva lectura cultural del territorio donde el espacio deja de ser un simple contenedor físico. De esta manera y sobre la base conceptual que señala que todo conocimiento es subjetivo, se levanta un nuevo enfoque centrado en la tradición geográfica que representa la antítesis a la visión objetiva, restringida, mecanicista y determinista propia del pensamiento positivista. De esta forma, los significados, los valores, las metas y las intenciones se convierten en el foco principal de estudio de la visión humanista en geografía.

De hecho, la expresión geografía humanística ( $b u$ manistic geography) surge a partir de la obra editada con el mismo nombre por Ley y Samuels en 1978, que de alguna manera, representa la institucionalización de esta corriente de pensamiento. Sin embargo, Santis y Gangas
(2004) sostienen que el enfoque humanístico en geografía debe sus orígenes a la obra de Johnston, quien en los años 1979 y 1983 sistematizó los primeros modelos y paradigmas con los que los geógrafos afrontaron los preceptos fundamentales de la visión humanística del espacio. Sin embargo, para Estébanez (1982), los orígenes más recónditos del humanismo en geografía se localizan en la obra de Hardy llamada La géographie psychologique, editada en 1939, largamente silenciada y criticada por Demangeon, Wright y Sauer, entre otros.

La geografía humanística en este contexto, adoptaba una entidad ideográfica o de investigación de valores (idios) en detrimento de la visión nomotética (leyes) propia de la geografía cuantitativa. Así las cosas, la descripción, la explicación y la interpretación de la vivencia individual y colectiva del espacio geográfico representan su objeto de estudio principal.

De igual forma, geógrafos como Relph, Ley, Samuels, Entrikin, Yi-Fu Tuan y Buttimer situaron la geografía entre las ciencias sociales no positivistas, con vistas a reconciliar su doctrina y preceptos básicos con la comprensión de la situación del ser humano en el mundo desde un punto de vista de interpretación más que de explicación causal.

El objetivo terminal de la geografía humanística debía situarse en el desarrollo de un tipo de conocimiento verdaderamente personal, en el que tengan cabida la emoción y el pensamiento, la pasión y la razón, para que, en conjunto, conduzca a la mejora de la comprensión de uno mismo y del mundo que lo acompaña (Buttimer, 1976). La utilidad de la geografía humanística radica en el esclarecimiento del significado, los conceptos, los símbolos y las aspiraciones de las personas o grupos en relación con el espacio o el lugar (Tuan, 1976). Así las cosas, la experiencia del espacio y la carga de significado que le resulta inherente, o bien la relación y posterior interpretación que del mundo hacen los individuos, centran la atención de los geógrafos humanistas.

La comprensión del significado del mundo y en particular, del significado otorgado a los lugares por parte de los individuos, así como la introspección en el espacio vivido como experiencia del mundo de la vida (Lebenswelt), traslada la investigación geográfica hacia una fenomenología constitutiva proveniente del pensamiento de Husserl y Schutz, caracterizada por la búsqueda de significado. Para Unwin (1995), la aportación más genuina de Schutz se concreta en la definición de la intencionalidad de la acción humana, especialmente para comprender el significado social en el contexto del mundo vivido y no en el nivel trascendental más profundo de Husserl. Las obras de Tuan

$14 \&$ Universidad de San Buenaventura, Cali - Colombia 
Topophilia: a study of environmental perception, attitudes and values (1974) y de Relph Place and placelessness (1976), reflejan claramente el énfasis depositado en el estudio de los lazos existentes entre los individuos y el entorno que los rodea expresados en la definición del lugar.

La geografía humanística es, pues, una geografía antropocéntrica fundamentada en el existencialismo y en la fenomenología, en la que el espacio se convierte en lugar y la construcción social de los lugares se vehicula mediante una lectura de la carga emotiva, estética y simbólica que le es propia. En resumen, la geografía humanística se interesa en esclarecer cómo la gente interpreta el mundo y cómo se relaciona con él.

La geografía humanística propone un enfoque comprensivo, un conocimiento del espacio cercano a la empatía, mediante una experiencia vital concreta (Capel, 1981). Representa, entonces, el máximo exponente del descubrimiento de la subjetividad en geografía, así como de la experiencia personal iniciada por la geografía de la percepción y del comportamiento ambiental. Para este mismo autor, es mediante la concreción de determinadas geografías personales que los individuos organizan su comportamiento en el espacio. Así, los valores, el mundo de la vida y el espacio vivido se convierten en foco central de reflexión geográfica.

Metodológicamente, la geografía humanística ejecuta sus investigaciones mediante la encuesta antropológica, la observación participante o el trabajo de campo experiencial (Capel, 1981; Estébanez, 1982), la memoria histórica, la elaboración de una cartografía de la realidad (García-Ballesteros, 1992) y más recientemente, mediante las producciones de narrativas de vida espaciales, vinculadas a la emergencia de un determinado constructivismo geográfico (Lindón, 2008). En cuanto a las principales corrientes de pensamiento vinculadas ideológicamente a la geografía humanística, cabe citar la fenomenología o la comprensión de la esencia, el existencialismo centrado en la individualidad y el ser y, finalmente, el idealismo, que define la acción humana en relación con el desempeño de determinados ideales.

La fenomenología de Husserl y Shutz fue de las primeras en trasladarse al ámbito de la investigación geográfica a inicios de los años setenta del siglo XX. La de Schutz era una fenomenología constitutiva hacia la búsqueda de significado y las adhesiones por parte de geógrafos humanistas -sobre todo de Tuan, Relph y Buttimer- se produjeron con relativa celeridad. De hecho, la geografía humanística inscrita en la tradición fenomenológica se caracteriza, en primer lugar, por la preponderancia de la experiencia práctica con los lugares; en segundo lugar, por la delimitación de un objeto de estudio fundamental destinado a dar alcance, amplitud y profundidad al concepto "experiencia de vida con los lugares"; finalmente, una geografía que se pretende del mundo vivido debe determinar las conexiones existentes entre tipificaciones sociales del significado y los ritmos de espacio-tiempo de la acción, así como descubrir las estructuras de intencionalidad subyacentes (Gregory, 1981; Peet, 1998).

La vinculación más clara entre fenomenología y geografía humanística se produce mediante el concepto de "mundo vivido", centrado en los valores como elementos fundamentales de la totalidad de las experiencias, en las que el lugar es un importante centro de significado, de realidad personal y de vinculación emocional. Así pues, la potenciación del estudio de los lugares -el retorno al lugar- representa un ejercicio de humanización del estructuralismo (García-Ballesteros, 1992).

Por otra parte, el existencialismo se vincula sobre todo al concepto "espacio existencial" en que el individuo proyecta su existencia en un espacio determinado. Para Estébanez (1982) el existencialismo matiza algunos aspectos de la fenomenología de Husserl, sobre todo en el sentido de hacer notar que la existencia es anterior a la esencia y que el individuo, ante todo, existe, surge en el mundo y después se define a sí mismo. Así, el aspecto esencial del existencialismo vinculado a la geografía humanística se concreta en la comprensión de la estructura del espacio existencial, donde la distancia es una conexión afectiva y no métrica y el lugar se transforma en un conjunto de significados.

Finalmente, el idealismo representa una crítica más a la ilusión de la racionalidad. De hecho, la visión idealista del mundo observa la realidad mediante las construcciones que de esta hace la mente humana. Además, esta corriente de pensamiento propone una reflexión filosófica no a partir del mundo externo, sino del "yo", el sujeto o la conciencia (Estébanez, 1982). El idealismo, pues, se preocupa por la significación humana del espacio.

Capítulo aparte merece la aportación de Tuan (1976) relacionada con la experiencia del espacio. A partir de los conceptos "espacio", "lugar" y "experiencia", el autor desgrana el núcleo conceptual y metodológico de la geografía humanística. Destaca, por encima de todo, el concepto de experiencia o conocimiento del espacio, que implica, según Tuan, todo el resto de sentidos (olfato, gusto, tacto, oído) y no solo el de la vista. Por tanto, la dimensión del espacio tiene una clara implicación sensorial, pero 
también simbólica, ya que se vincula al efecto emocional de la percepción.

Tuan (1976) critica la descripción, a veces enciclopédica o excesivamente descriptiva, del territorio llevada a cabo por los geógrafos y los invita a impulsar una investigación de auténtica militancia, de experiencia directa con el espacio, de obtención de vivencias geográficas en primera persona. En este sentido y por el interés de vinculación de la geografía humanística al estudio de la comunicación del espacio turístico a priorie in situ, resulta necesario introducir el concepto de "constructivismo geográfico" vinculado a los hologramas socioespaciales y a las "narrativas de vida espaciales” sugeridas por Lindón (2007a , 2007b; 2008).

Así, la geografía humanística y también la geografía de la percepción han recibido buena parte de críticas basadas en una presunta ineficacia demostrada para la consolidación de una metodología que, de forma sistemática, permitiera obtener resultados periódicos relacionados directamente con la experiencia de vida individual con el entorno. Sin embargo, la observación participante ha sido una técnica de investigación tradicionalmente vinculada al análisis de la experiencia humana con el espacio. De hecho, se utiliza la encuesta antropológica o la memoria histórica, aunque da la sensación de que la geografía humanística no disponía en sus inicios de una metodología propia a partir de la cual instrumentalizar los resultados obtenidos.

Sin embargo, la construcción social de los lugares como resultado de una previa vivencia y experimentación en el nivel individual, implica un enfoque comprensivo de la vida cotidiana, aunque con la incorporación de un sesgo constructivista a partir del cual se conciben los lugares como una perpetua construcción social. En este sentido, Lindón (2007a; 2007b; 2008) plantea la incorporación del constructivismo geográfico como una forma más de acercarse al estudio del espacio vivido mediante el despliegue de metodologías cualitativas. En concreto, señala un par de estrategias metodológicas para superar el entramado metodológico propio de la geografía humanística: los hologramas socioespaciales y las narrativas de vida espaciales.

Lindón (2007a) mantiene la consolidación en el marco de fondo de la geografía humanística, de las miradas egocéntricas, de las geografías de los mundos interiores. Es a partir de esta nueva concepción propia de la geografía de los espacios vividos que Lindón justifica la unión de intereses con el constructivismo. Esto es así porque -tal y como hace notar la misma autora- en los últimos años, la geografía y sobre todo su investigación asociada, tal vez se ha preocupado más de teorizar que de ofrecer una salida metodológica viable el estudio de las geografías personales.
La anexión al enfoque constructivista también intenta dar respuesta a preguntas del tipo: ¿cómo observar y registrar lo que no es material proveniente de la espacialidad? ¿Desde qué punto de vista se observa?

Aunque existen pocos precedentes de vinculación de la tradición geográfica al constructivismo, tal y como hace notar Lindón (2007a), Ley y Samuels (1978) ya anticipaban las posibilidades de estudio de la perspectiva de la construcción social de la realidad desde la espacialidad, para pasar a hablar abiertamente de la construcción social de los lugares. De hecho, el replanteo de estudio del espacio desde la perspectiva del sujeto que lo experimenta sitúa sus orígenes en el llamado cultural turn (giro cultural), experimentado por la geografía anglosajona a finales de los años ochenta del siglo XX, que supone, esencialmente, la incorporación de la no materialidad al estudio del espacio y la espacialidad.

El giro cultural pone el énfasis en la concepción del espacio como experiencia (Tuan, 1977) y a partir de ahí, el estudio del lugar como construcción social adopta una relevancia inusual en la tradición geográfica anterior. La construcción social de los lugares no excluye la materialidad, pero advierte de la necesidad de estudiar los significados que se derivan. Los "imaginarios urbanos" trabajados por Armando Silva (1997) representan un buen ejemplo de búsqueda de significados individuales interiorizados del espacio urbano o metropolitano. Por tanto, la espacialidad de la vida cotidiana se sitúa a medio camino entre lo imaginario y lo real. Asimismo, y según Ortega-Valcárcel (2000), las geografías humanísticas abren la puerta de buena parte de las expectativas geográficas contemporáneas, especialmente en cuanto a la búsqueda de las dimensiones simbólicas del espacio, las particularidades de los lugares y la relación entre espacio y sujeto. En resumen, el enfoque humanístico en geografía se interesa por los espacios personales específicos, por el espacio vivido y por los signos de identidad personal y subjetiva con los lugares.

La geografía humanística contemporánea más actual cuenta con la contribución de algunos geógrafos que, en buena medida, son discípulos de Yi-Fu Tuan, considerado como uno de los padres de la geografía humanística. Con posterioridad a su aparición (entre los años sesenta y setenta del siglo XX), la geografía subjetiva entró en un periodo de olvido y declive que se prolongó hasta los años noventa, justo cuando el posmodernismo y su ideología asociada permitían un resurgimiento de los enfoques subjetivos en geografía. Tanto es así, que los conceptos "lugar", "espacio" y "espacialidad" han sido, de algún

$16<$ Universidad de San Buenaventura, Cali - Colombia 
modo, refundados en el marco de la contemporaneidad (Delgado, 2003).

La refundación de la geografía humanística encabezada, entre otros, por Robert David Sack y su obra Homo geographicus (1997), desarrolla muchos de los conceptos apuntados en primera instancia por Tuan. Por ejemplo, en Homo geographicus Sack explora y se sumerge en la naturaleza geográfica de los individuos como elemento de centralidad de la existencia humana mediante una reelaboración de la experiencia cotidiana de ser en el mundo. Por todo lo expuesto, la experiencia humana con el espacio y el lugar, o dicho de otra manera, la respuesta a la pregunta de cómo los individuos experimentan y entienden el mundo desde un posicionamiento experiencial, se vehicula a partir del concepto de lugar, concebido a modo de centro y objetivo esencial de conocimiento geográfico.

\section{El constructivismo geográfico y la delimitación de metodologías de análisis del mundo vivido}

El interés por vincular las geografías personales a la aproximación del estudio de la experiencia vivida por el individuo con el espacio geográfico y simbólico en el marco de la comunicación del espacio turístico, radica en la necesidad de determinar metodologías de análisis que permitan examinar el significado de la inmaterialidad geográfica, del intangible geográfico, así como del significado simbólico atribuido subjetivamente al espacio a partir de la perspectiva aportada por la experiencia espacial del sujeto. En este sentido, las propuestas de Lindón (2007a, 2007b, 2008) vinculadas al análisis de la construcción social de la espacialidad y, por tanto, a un análisis de tipo constructivista con metodologías de estudio concretas, como son los hologramas socio-espaciales y las producciones de narrativas de vida espaciales, parecen enormemente pertinentes para el análisis aplicado de la experiencia individual con los lugares desde la aportación disciplinaria de la geografía.

Para Lindón (2008) el constructivismo geográfico o espacial permite la introducción en la comprensión individual del espacio a partir de coadyuvar el análisis material e inmaterial de la espacialidad geográfica, todo ello desde el punto de vista de la experiencia espacial del sujeto. Así, la aportación del constructivismo geográfico se centra en intentar averiguar cómo es la vivencia del individuo desde la visión del sujeto que habita el lugar. Esta mirada es reconstruida y reinterpretada por el geógrafo en el camino por conocer la experiencia espacial del otro.
Así, la mirada cualitativa facilitada por el constructivismo geográfico permite adentrarse en la reconstrucción de la espacialidad que puede ver y sentir un sujeto desde algún lugar y no limitarse a hacer descripciones a vista de pájaro ajenas al sujeto, de la experiencia con el espacio. Una primera propuesta de desarrollo metodológico se concreta en el diseño de hologramas socioterritoriales para habilitar vías de comprensión del proceso de construcción social de espacios vividos particularmente. El holograma, pues, tiene encomendada la misión principal de hacer emerger y reconstruir imágenes con voluntad interpretativa que, de otro modo, no se percibirían con un trabajo de observación cotidiano.

De esta manera, el despliegue de hologramas cualitativos se vehicula a partir de la captación de las narrativas de vida que se producen en interacción con el investigador. Con posterioridad, se ejecuta un proceso de desciframiento y decodificación que intenta ir más allá de las palabras y de la mera transcripción. Se pretende acceder a los significados escondidos detrás de determinadas verbalizaciones, para crear una trama de significados. La conexión metafórica de significados es lo que permitirá desentrañar la vivencia y la significación espacial e individual de la experiencia geográfica. Por tanto, el holograma socioespacial se convierte en una propuesta metodológica abierta a la interpretación espacial (Lindón, 2007a, 2007b).

Lindón (2007a) considera que la habilitación de hologramas socioespaciales permite una interpretación de la vivencia de los lugares a dos niveles. Un primer nivel, se corresponde con una interpretación espacial localizada, que parte del lugar en el que se ubica la narrativa. El segundo nivel de interpretación, emerge de la conexión existente entre el lugar en el que se encuentra anclada la narrativa de vida y otros lugares distintos y distantes, lo que constituye un conjunto de experiencias con el entorno conformadoras de la espacialidad de los habitantes. Es a partir de aquí que los hologramas espaciales permiten comprender diferentes formas de relación del sujeto con sus espacios de vida.

Así, Lindón (2007a) asegura que "este recurso metodológico tiene una enorme potencialidad, porque permite observar lo minúsculo para, desde allí, desentrañar las tramas de significaciones y los lugares parcialmente visibles en los que estas se objetivan." (p, 12). En efecto, la investigación geográfica cualitativa da, en este contexto, un paso más en la profundización y la concreción de técnicas de investigación social que permitan adentrarse en la vivencia del mundo por parte de los individuos. De esta forma se resuelve -en palabras de Lindón (2008)- la "trilogía de 
investigación" asociada a la experiencia humana con el mundo, a saber: formas espaciales, prácticas espaciales y significados de los lugares.

Como se ha podido ver hasta ahora, la problemática principal en el intento de objetivar y analizar una práctica humana genuinamente subjetiva se encuentra en la efectiva captación de las prácticas espaciales. En este sentido, Lindón (2008) señala tres posibles caminos de investigación: la observación de las prácticas y su espacialidad; dar cuenta de estas mismas prácticas mediante su asociación a imágenes diversas y, finalmente, una tercera vía concretada en el análisis del discurso del mismo sujeto implicado en estas prácticas, es decir, prestar atención a los relatos y a los discursos sobre los espacios de vida y vividos, esto es, las narrativas de vida espaciales, las cuales no deben confundirse con las entrevistas convencionales. El desarrollo de este "pensamiento narrativo" permite la construcción de significados de las propias experiencias vividas en el nivel individual.

A partir de aquí, la construcción de certezas surge de la propia narración. De hecho, Lindón (2008) define las narrativas de vida espaciales de la siguiente manera: "Es un relato organizado y secuencializado espacio-temporalmente de experiencias vividas por el sujeto en ciertos lugares. Es un relato en el cual el influye de alguna forma en la experiencia individual, le imprime una marca" (p. 20).

El advenimiento de una "sociología de los espacios" ha abierto la puerta al entendimiento de los lugares como resultado de una determinada construcción social, tanto en el nivel individual como en el colectivo. Paralelamente, la necesidad de definición de enfoques -eminentemente cualitativos- para definir la lógica de creación de determinados constructivismos geográficos, ha posibilitado lo que Lindón (2008) considera como una "refundación del saber geográfico", cuando la disciplina adopta un sentido claramente contemporáneo y de enfatización de su vocación social.

Este giro de la geografía se vehicula a partir de tres constataciones particulares: el renovado acercamiento (en el nivel metodológico y no solo teórico), de la ciencia geográfica hacia ámbitos de estudio de tipo experiencial, subjetivo y cualitativo en sentido amplio; la producción de nuevo conocimiento geográfico a partir de la aplicación empírica de vivencias, experiencias y reflexiones vinculadas a los espacios y a los lugares, y, finalmente, la renovada asunción de los desafíos que supone abordar lo material y lo no material que abren, a su vez, la puerta a la interdisciplinariedad, concretada, por ejemplo, con el desembarco en el puerto de la ciencia geográfica de la so- ciología interaccionista y fenomenológica, de la psicología cognitiva y social o bien de la antropología sensible a todo lo simbólico, en definitiva, aquello no material que forma parte de la espacialidad (Lindón, 2008).

En esta disyuntiva, el constructivismo geográfico, de especial interés para el objeto de estudio que ocupa estas páginas, incorpora la consideración de la materialidad y la inmaterialidad del espacio geográfico que supone la exploración de la espacialidad de la vida social mediante el mundo del individuo, a través de su mundo interior. A partir de aquí, el constructivismo geográfico encuentra en la investigación cualitativa una renovada producción de conocimiento espacial. Así, tanto las narrativas de vida espaciales como los hologramas socio territoriales se conciben a modo de ventana a través de la cual se vislumbran formas de espacialidad más complejas, en función de su componente experiencial (Lindón 2007a y 2007b).

El desafío metodológico planteado en el acceso a las geografías personales o del mundo interior radica en la búsqueda de cómo los sujetos llegan a construir un insideness (interioridad), esto es, un constructor de sentido dentro de un outsideness (exterioridad). En el contexto descrito, los hologramas socioterritoriales y las narrativas de vida espaciales devienen dos respuestas concretas al reto metodológico planteado con motivo del estudio del espacio y, por extensión, de la espacialidad, a modo de lugares socialmente construidos y no como simples estructuras geométricas (Lindón, 2007a).

\section{Posmodernismo y geografía}

La posmodernidad representa, de algún modo, un periodo de continuidad a la respuesta reaccionaria contra la concepción lineal del progreso, la sistematicidad, la objetividad, la racionalidad o la verdad de la ciencia (Pillet, 2004). A partir de aquí, se puede hablar abiertamente de posmodernismo humanístico, dado que los postulados más recientes vinculados a las geografías del sujeto se nutren, en muy buena medida, de los nuevos enfoques provenientes de la ideología posmodernista.

En efecto, el posmodernismo representa un periodo de continuidad en la ruptura con los postulados empíricos y de exaltación, en todo caso, de la incredulidad, del escepticismo y el eclecticismo. Sus principales avaladores son Foucault, Lyotard y Baudrillard (Pillet, 2004). La llegada del posmodernismo se considera, a todos los efectos, una oportunidad para las geografías del sujeto, en especial por el hecho de que el núcleo de pensamiento posmodernista 
coincide, en muchos aspectos, con la esencia del humanismo en geografía.

Concretamente, la coincidencia de intereses entre los posicionamientos humanísticos y los posmodernistas se produce en la valoración compartida y prioritaria hacia el individuo, así como de sus vivencias y emociones personales, de sus interpretaciones particulares del entorno, de la contemplación del espacio como un texto susceptible de múltiples interpretaciones y reinterpretaciones (OrtegaValcárcel, 2000). La etapa posmoderna es también la etapa de la posfenomenología y el posexistencialismo, un período que se caracteriza por volver a empezar desde cero, para deconstruir lo que hasta ahora se había construido.

Así las cosas, se consolida una geografía multidisciplinar abierta a otras perspectivas y enfoques, a un análisis poliédrico de las diferentes espacialidades existentes. En definitiva, se instaura una geografía que sigue preocupada por la dimensión imaginaria del espacio y el análisis de los textos, así como para el estudio de los símbolos y de los espacios simbólicos. Por tanto, la defensa de la diferencia, la flexibilidad, la subjetividad, la discontinuidad o la fragmentación, se integran en la ideología básica del pensamiento posmodernista.

En este contexto, Soja (1996), uno de los geógrafos más destacados del posmodernismo, señala el advenimiento del tercer espacio (thirdspace), entendido como un camino alternativo a partir de la contemplación, la interpretación y la intervención, con el fin de cambiar el entorno espacial de la vida humana. Se trata, asimismo, de un espacio fragmentado, de la diferencia, de las minorías, de las mujeres y de la lucha por la igualdad social (Ortega-Valcárcel, 2000).

Igualmente, son muchos los autores que están de acuerdo en afirmar que la etapa posmodernista y su lectura geográfica, surgen en la transición de los años ochenta a noventa del siglo XX, como resultado de la crisis fordista y del sentimiento unánime de la necesidad de un cambio de modelo. Aparte de Soja (ya mencionado con anterioridad), Olsson (1997) es otro de los geógrafos más representativos de la etapa posmodernista, quien consideraba que la geografía es la cartografía del pensamiento y de los mapas invisibles. Una geografía que desmonta los espacios del lenguaje y el lenguaje del espacio, sensible a los lugares $\mathrm{y}$ a las lenguas.

Es así como la geografía del posmodernismo se ocupa preferentemente de la exploración de nuevos espacios, a saber: los espacios de la diferencia, los espacios al margen, del olvido. Se preocupa también de la decodificación del discurso geográfico y de su interpretación. El posmodernismo en geografía, se convierte así en una apertura hacia la superación de determinadas fronteras que históricamente se habían impuesto en la investigación geográfica. El posmodernismo también se asocia a la crisis del proyecto ilustrado de la modernidad en la filosofía, la cultura y la ideología, y muestra un gran interés por nuevos lenguajes $\mathrm{y}$ formas de representación, por el fin de las verdades absolutas y por la deconstrucción de viejas teorías y métodos (Albet, 1994). El posmodernismo aboga por la aparición de nuevos valores y actitudes ante la vida, en el marco de una revolución social que se manifiesta con especial incidencia en los ámbitos de la información y el consumo.

Por todo ello, el posmodernismo en geografía se ha traducido en una renovada atención a las problemáticas que caracterizan el lenguaje y las formas de expresión y representación del mundo y de la experiencia temporal y espacial vivida. Ofrece preponderancia al espacio y a la dimensión espacial (geografía) por encima del tiempo y la dimensión temporal (historia) y ha contribuido a la introducción de la teoría feminista en la geografía, además de revalorizar la esfera local (nueva geografía regional y estudio de las localidades). En conjunto, apuesta por la búsqueda de fórmulas alternativas más flexibles que faciliten la comprensión de las nuevas relaciones generadas entre espacio, tiempo y sociedad.

El posmodernismo en geografía representa, pues, la voluntad de seguir indagando en las geografías de la experiencia humana con los lugares; de descubrimiento de los significados inmateriales asociados al espacio; de exaltación de la importancia de la geografía sensorial, y, en definitiva, de lectura e interpretación de la vivencia de la sociedad con los espacios que le son propios y ajenos. Las geografías del sujeto (percepción, humanismo y posmodernismo) adoptan una importancia capital para la naturaleza espacial del objeto de estudio aquí planteado, esto es, la percepción y vivencia del lugar en la estrategia de comunicación del espacio turístico.

\section{Las geografías emocionales}

Históricamente, el estudio de las emociones se ha vinculado a cuestiones esotéricas (Anderson y Smith, 2001) cercanas a la metafísica, lo que representa la administración injusta de un saber que se presume decisivo en la introspección hacia una geografía de los sentimientos, de las emociones, de la afectividad. En efecto, la investigación relacionada con aspectos vinculados a la emoción ha sido generalmente silenciada, a pesar de representar un 
extraordinario hilo conductor de las vivencias experimentadas por la humanidad.

La emoción se ha mantenido en una esfera privada alejada de la vida pública y más aún, del objeto de interés de la investigación académica. Las causalidades deben buscarse, en opinión de Anderson y Smith (2001), en las bases de género de la producción del conocimiento. Esto significa que la racionalidad y la objetividad se han asociado históricamente a la masculinidad, mientras que la subjetividad, la pasión y el deseo han sido habitualmente devaluadas al tratarse de valores asociados a la feminidad. La aportación específica de la tradición geográfica hacia una revalorización del papel desempeńado por la emoción en los diferentes campos de investigación aplicada, encuentra en los "espacios emocionales", interesantes perspectivas de estudio.

El reconocimiento de la variable emoción en el contexto de la contemporaneidad y, especialmente, su aportación a la globalidad del saber geográfico, parece ser el primer paso hacia su legitimación. En este sentido, Anderson y Smith (2001) señalan que, si bien el poder de las relaciones emocionales no puede obviarse, es necesario establecer rigurosas metodologías de trabajo a partir de las cuales implementar un cambio conceptual en el tratamiento académico otorgado en los últimos tiempos a la emoción.

No hay duda de que, en este sentido, el contexto de la ciudad contemporánea, la posmodernidad y, en definitiva, la economía del simbolismo, ha provocado la emergencia de variables vinculadas a la experiencia personal y grupal, a la empatía, al afecto y a la emoción. Thien (2005), señala una cierta explosión a comienzos del siglo XXI, de la intersubjetividad vinculada a la creciente relevancia adoptada por las geografías sociales, culturales y de género. Esto puede deberse, según la misma autora, al renovado interés dispensado al cuerpo como discurso, al creciente consumo de cultura y, en definitiva, al progresivo proceso de comercialización de las emociones (Nogué \& San Eugenio, 2011).

Las geografías emocionales pueden ampliar su área de influencia hacia aspectos relacionados con la geografía, los estudios de género, los estudios culturales, la sociología o la antropología, así como cualquier otra disciplina que ayude a entender cómo el mundo se encuentra mediatizado por los sentimientos (Thien 2005). En este contexto, las geografías simbólicas o la denominada geografía de la emoción, las cuales representan la búsqueda de los vínculos afectivos de las sociedades con sus espacios o bien el estudio de la experiencia que proporciona la interacción con el lugar, emergen con fuerza como objeto de estudio propio de la geografía (Davidson, Bondi y Smith, 2005).

Si a todo ello se une el creciente interés procedente del ámbito de la publicidad, el mercadeo y el branding en su aplicación a la esfera territorial, se puede vislumbrar la vinculación disciplinaria actual que se establece entre un dominio de interés emergente en geografía (geografía de la emoción) y la proliferación de estrategias comunicativas de tipo persuasivo y emocional que tienen al espacio geográfico y simbólico como marco de fondo.

De hecho, la pertinencia de inclusión de las geografías emocionales en el ámbito de la percepción y vivencia del lugar en la comunicación del espacio turístico se justifica, precisamente, a partir de esta constatación; esto es, de la comprobación de cómo la emoción implícita en el territorio es usada con intereses comerciales para atraer no solo turistas, sino también empresas, talento e inversión, para posibilitar la delimitación de un nuevo contexto de trabajo en el que la emoción de los espacios, vehiculada en algunos casos mediante procesos de mercadeo, branding y comunicación, deviene un importante elemento definitorio para una posterior toma de decisiones.

La geografía emocional evoluciona a partir de una tendencia en geografía que, como ya se ha constatado en apartados anteriores de este mismo artículo, tiende a priorizar el estudio del sujeto en su interacción con el espacio geográfico. Sin embargo, la geografía, con anterioridad a la revolución cognitiva y al interés por el estudio de la vivencia personal del territorio, había tendido a negar, evitar, minimizar o, directamente, obviar sus implicaciones de análisis emocional. La geografía, al igual que sucede en otras disciplinas, expresa emociones y este hecho se hace evidente a partir de lo que se desprende de la escritura que relaciona la gente y los lugares, en los que la aparición de la vertiente emocional está a menudo presente. En definitiva, la presencia de la emoción en nuestras interpretaciones, entendimiento y lectura del mundo, hace necesaria su inclusión en el pensamiento geográfico (Davidson, Bondi, \& Smith, 2005).

En efecto, la espacialidad y la temporalidad de las emociones, o bien la importancia simbólica de los lugares, proviene de la asociación emocional que se le vincula y de los sentimientos de miedo, temor, preocupación, alegría o satisfacción que inspiran. Por esta razón, la geografía emocional debe entender la emoción desde un punto de vista experiencial y conceptual, mediante la articulación de una lectura socioespacial de los estados mentales interiorizados por los sujetos. 
Así pues, el estudio de la espacialidad de la emoción se vehicula mediante tres enfoques fundamentales: el estudio de las geografías de la salud y del cuerpo; el abordaje de las geografías de la identidad y de las relaciones sociales, esto es, determinar de qué manera las emociones emergen como resultado de la interacción entre las personas y el entorno, y finalmente, a través de una propuesta de solución a la problemática inherente a las formas de representación de la emoción.

Urry (2005) explica la emoción implícita en el espacio mediante su conocida teoría vinculada a la mirada del turista. En efecto, el placer visual, la visión de una mirada especializada e inmortalizada a partir del visionado o bien mediante la captación de fotografías de un paisaje considerado bello in situ. De esta manera, Urry (2005) asegura que los sitios no se pueden considerar espacios cartesianos definidos a partir de coordenadas geométricas. Así, la transformación de los espacios en recintos de consumo provoca la emergencia del factor emocional inherente a la espacialización. Por lo tanto, el placer que se asocia a estos lugares proviene del consumo de bienes y servicios que, de alguna manera, representan los lugares.

Mediante el consumo de bienes y servicios el lugar se convierte en experiencial. En este punto, Urry (2005) hace notar la existencia de una fractura o gap esencial en la emoción comunicada y la emoción vivida de los lugares, esto es, la anticipación de los placeres que esperan a futuros visitantes a partir del consumo de un determinado espacio (nivel a priori) puesto en relación con la experiencia efectivamente vivida en primera persona con los lugares (nivel in situ). La consideración de este aspecto en el contexto de la comunicación del espacio turístico pre y pos visita, resulta clave para el objetivo de estudio del presente trabajo.

De hecho, el mismo Urry (2005) establece una clasificación relacionada con la lógica de consumo emocional de los espacios por parte de la sociedad basada en tres aspectos fundamentales. En primer lugar, menciona la importancia que la disposición de los objetos tiene para la naturaleza de los lugares, como por ejemplo la relacionada con el simbolismo inherente a determinadas infraestructuras, como el Museo Guggenheim, que se convierte en un ejemplo clásico de reposicionamiento de la ciudad de Bilbao, del establecimiento de un icono anclado en el territorio e ideado por un arquitecto célebre (Calatrava), a partir del cual la ciudad vasca proyecta su identidad a escala global. En segundo lugar, considera que los lugares se diferencian en términos de si son temporalmente ricos o pobres, de si están de moda o no, de si presentan o no oportunidades cosmopolitas. Finalmente, y en tercer lugar, el autor menciona el criterio de proximidad geográfica, de interconectividad y de movilidad entre territorios, en el cual la proximidad a centros globales operacionales determina su éxito o fracaso.

Para Urry (2005), en definitiva, el placer inherente a los espacios deriva, en parte, de las emociones envueltas en el consumo visual de los lugares. El criterio de movilidad, tan característico de la "modernidad líquida" expuesta por Bauman (2003), ha fomentado una inusual capacidad para el juicio estético del territorio, que, a su vez, alimenta y anima el turismo mundial así como el movimiento ecologista. Es a partir de aquí que Urry (2005) asegura que el destino de las sociedades actuales se encuentra en la búsqueda del placer existente en los lugares (hedonismo), mediante una economía implacable de signos visuales, mientras que el resto de sentidos se movilizan en los márgenes, a modo de resistencia ocasional. Los lugares, pues, disponen de un conjunto de características abstractas circunscritas a un mundo móvil, aunque cada vez son más difíciles de apreciar. En este contexto, la emoción del turismo se concibe a partir de la habilitación de una "habitación con vistas", lo que antes habían sido las antiguas postales.

El desembarco de las geografías emocionales en el saber geográfico puede considerarse una consecuencia directa del relanzamiento de las geografías subjetivas iniciadas con la percepción y el humanismo en geografía. De hecho, la aparición en 2009 de la revista científica de alcance internacional Emotion, Space and Society, ocupada en publicar trabajos de investigación inéditos relacionados con la espacialidad de la emoción, el sentimiento y el afecto, y por tanto, de temática directamente relacionada con la interacción resultante de la sociedad con sus espacios, muestra un creciente interés de la comunidad científica internacional por la investigación de la vinculación de la emoción con el espacio y las personas.

De hecho, y de forma paralela, en 2009 se constituyó la Society for the Study of Emotion, Affect and Space (SSEAS), la cual se erige actualmente a modo de clúster de conocimiento en torno a las geografías emocionales. Esta misma asociación propone algunos de los ámbitos de investigación vinculados a la geografía emocional, que son, entre otros, los siguientes: espacios afectivos y globalización, arraigo frente a desarraigo, arquitecturas emocionales y paisajes de la emoción, la semiótica y la poética del afecto y de la emoción, espacio público y emoción o política y emoción, entre otros (Nogué, 2009). 
Existe también, tal y como hace notar Nogué (2009) dentro y fuera del ámbito académico, un renovado interés por aproximarse a la vinculación de las emociones de los lugares, los paisajes y, en general, a la gestión del espacio público. Este nuevo interés se concreta en la proliferación de publicaciones ocupadas en determinar la afección emocional de los sujetos con los lugares, como lo demuestra la aparición de la obra Emotional Geographies editada en 2005.

Nogué (2009) considera que la emergencia con energía renovada de la temática que vincula la emoción con el espacio se debe, en buena medida, al rechazo a una postura simplista partidaria de la reducción de la realidad a una interpretación de naturaleza matemática y geométrica del territorio, que deja de lado, por tanto, aspectos como los colores, los sabores, los olores o bien la experimentación del sentido de la belleza en todas sus consecuencias y matices. Es a partir de estas constataciones que procede el retorno de las emociones a la esfera pública. De hecho, el mismo autor explica que la vida tiene una condición espacial y emocional innata.

Nogué (2009) finalmente, justifica así la importancia de la emoción en el marco de estudio de los lugares y de la disciplina geográfica:

Interactuamos emocionalmente y de manera continua con los lugares, a los que imbuimos de significados que retornan a nosotros a través de las emociones que nos despiertan. La memoria individual y colectiva, así como la imaginación, más que temporales, son espaciales. [...] Experimentamos emociones específicas en distintos contextos geográficos y "vivimos" emocionalmente los paisajes porque éstos no son sólo materialidades tangibles, sino también construcciones sociales y culturales impregnadas de un denso contenido intangible a menudo solamente accesible a través del universo de las emociones. [...] La geografía como disciplina no podrá despojarse nunca de su dimensión emocional, por más que algunas escuelas lo hayan intentado a lo largo de su dilatada historia. Las topografías de la vida cotidiana están demasiado impregnadas de emoción y sentimiento y nuestros tratados de geografía no dejan de ser, en el fondo, una especie de psicogeografías personales y sociales (pp. 4-8).

\section{Conclusiones}

Las geografías personales, representadas por la percepción, el humanismo, el posmodernismo y la emoción en geografía, implican la introspección desde el ámbito del territorio a las vivencias y experiencias individuales y colectivas que mantiene la humanidad con sus entornos. En este sentido, las bases geográficas que permiten descubrir los componentes de percepción y vivencia individual del lugar en el marco de la comunicación del espacio turístico; o, dicho de otro modo, la contribución de la geografía al análisis teórico de la comunicación del espacio turístico desde el punto de vista de la experiencia individual con el lugar, se implementa a partir de la relación sujeto-territorio.

En este sentido, las perspectivas de estudio iniciadas con la geografía de la percepción se ven afianzadas por la geografía humanística, que propone un enfoque comprensivo de la vivencia individuo-territorio, mediante una experiencia vital concreta donde la clave se encuentra en el análisis de la experiencia personal. En esta tesitura, lo que interesa averiguar son los significados y las valoraciones que la humanidad considera de sus espacios vividos. El sentido de lugar es un aspecto íntimamente vinculado a la vivencia espacial, a la introspección hacia la mente humana, a la comprensión de determinados comportamientos ambientales, a la decodificación, en definitiva, del simbolismo y significado implícito en el espacio vivido.

Asimismo, uno de los conceptos clave de la geografía humanística es el de "lugar", por sus connotaciones de "mundo de significados", o sea, de determinación de la experiencia significativa del sujeto con los lugares, así como de experimentación de su pertenencia a un determinado emplazamiento. Por lo tanto, de lo que se trata es de comprender en profundidad como el espacio se convierte en un centro de significados a nivel personal y colectivo (Bertrand, 1987).

Sin embargo, la dificultad metodológica de las ciencias inductivas se encuentra en el análisis y sistematización de las investigaciones de tipo cualitativo llevadas a cabo con el mundo vivido por el individuo, a fin de establecer parámetros de interpretación de la vivencia y experiencia que la humanidad mantiene con el espacio geográfico que lo rodea. En este sentido, además de la observación participante y la encuesta antropológica, se han mostrado dos propuestas innovadoras para el descubrimiento de los significados y simbolismos que la humanidad otorga a su entorno próximo y lejano. Se trata de los hologramas socioterritoriales y las narrativas de vida espaciales, propuestas por Lindón (2007a, 2007b, 2008).

Finalmente, las geografías emocionales -una corriente de pensamiento de incorporación reciente a la tradición en geografía- escenifican, de algún modo, la unión de las variables vivencia, experiencia, espacio y emoción. Y este es un extremo especialmente pertinente para la constitución de un aparato teórico interdisciplinario con capacidad para afrontar el estudio de la experiencia individual y en 
primera persona con los lugares. De hecho, en el ámbito corporativo, se habla a menudo de branding emocional (Gobé, 2005), que representa la evolución natural y el actual fin de trayecto de las estrategias de marca comercial a la vanguardia de la innovación.

Cuando Gobé (2005) menciona el término "emocional", se refiere a la forma a través de la cual una marca atrapa a los consumidores a nivel de sus sentidos y emociones. Pues bien, la geografía emocional posibilita una correlación con los territorios, de tal forma que su estudio debe permitir discernir cómo la humanidad se siente cautivada por simbolismos, significados y, en definitiva, por las emociones que se desprenden de un determinado emplazamiento geográfico. El branding emocional de territorios se lee y se vehicula, en muy buena medida, mediante la inteligibilidad aportada por la lectura y consideración de la emoción en geografía. Monerris (2009) expresa de forma clarividente las connotaciones asociadas a lo que él denomina como "geoemoción":

Los lugares son experiencias que se construyen desde sensaciones que elaboramos para darles un significado. Un lugar no se entiende, sino que se vive. [...] Un lugar no es geografía física, sino geoemoción, emoción implantada en un espacio. A partir de ello construimos el recuerdo, que debería ser una impronta indeleble y significativa. [...] El lugar es recuerdo cuando ha sido vivido, pero también es aspiración cuando lo hemos experimentado de forma vicarial, a través de los medios o de las representaciones. A partir de esas imágenes, elaboradas y mediatizadas, el lugar se convierte en mito o casi leyenda (Monerris, 2009, S. P.).

\section{Referencias}

Albet, A. (1994). Geografía, postmodernisme, geografía postmoderna: Aportacions al debat. Documents d'Anàlisi Geogràfica, 24, 7-11.

Anderson, K., \& Smith, S. J. (2001). Emotional geographies. Transactions of the Institute of British Geographers, 26(1), 7-10.

Bailly, A., \& Oya, J. (1979). La percepción del espacio urbano: Conceptos, métodos de estudio y su utilización en la investigación urbanistica. Madrid: Instituto de Estudios de Administración Local.

Bauman, Z. (2003). Modernidad líquida. México: Fondo de Cultura Económica.

Bertrand, C. (1987). Elsentido de la naturaleza. La geografia humanista. Tesis doctoral. Madrid: Universidad Complutense de Madrid.

Buttimer, A. (1976). Grasping the dynamism of lifeworld. Annals of the Association of American Geographers, 66(2), 277-292.
Capel, H. (1981). Filosofia y ciencia en la geografia contemporánea. Barcelona: Barcanova.

Davidson, J., Bondi, L., \& Smith, M. (2005). Introduction: Geography's Emotional Turn. En J. Davidson, L. Bondi \& M. Smith (Ed). Emotional Geographies (pp. 1-16). Aldershot: Ashgate.

De Castro, C. (2005). Geografía de la percepción como instrumento de planeamiento urbano y ordenación territorial. En II Jornadas de geografía urbana: recuperación de centros históricos, utopia, negocio o necesidad social. La geografia de la percepción como instrumento de planeamiento urbano y ordenación. Las fachadas urbanas, maritimas y fluviales ( $p$ p. 241-253). Alicante: Universidad de Alicante.

Delgado, O. (2003). Debates sobre el espacio en la geografia contemporánea. Bogotá: Universidad Nacional de Colombia.

Estébanez, J. (1979). Consideraciones sobre la geografía de la percepción. Paralelo, 37(3), 5-22.

Estébanez, J. (1982). La geografía humanística. Anales de geografia de la Universidad Complutense, 2, 11-31.

García-Ballesteros, A. (1986). Teoría y práctica de la geografía. Madrid: Alhambra.

García-Ballesteros, A. (1992). Geografía y humanismo. Vilassar de Mar: Oikos-Tau.

Gobé, M. (2005). Branding emocional: El nuevo paradigma para conectar las marcas emocionalmente con las personas. Barcelona: Divine Egg Publicaciones.

Gómez Rojas, J. C. (2006). El espacio vivido, una geografía para la vida. En C. Contreras, \& B. A. Narváez (Eds.) La experiencia de la ciudad y el trabajo como espacios de vida (pp. 15-43). Tijuana: Plaza y Valdés.

Gregory, D. (1981). Human agency and human geography. Transactions of the Institute of British Geographers, 6(1), 1-18.

Ley, D., \& Samuels, M. S. (1978). Humanistic geography: Prospects and problems. London: Croom Helm.

Lindón, A. (2007a). El constructivismo geográfico y las aproximaciones cualitativas. Revista de Geografia Norte Grande, 37, 5-21.

Lindón, A. (2007b). Los imaginarios urbanos y el constructivismo geográfico: los hologramas espaciales. Eure, 33(99), 31-46.

Lindón, A. (2008). De las geografías constructivistas a las narrativas de vida espaciales como metodologías geográficas cualitativas. Revista da ANPEGE, 4(3), 3-27.

Lowenthal, D. (1961). Geography, experience, and imagination: Towards a geographical epistemology. Annals of the Association of American Geographers, 51(3), 241-260.

Lynch, K. (1960). The image of the city. Cambridge: The M.I.T. Press. 
Monerris, A. (30 de diciembre de 2009). Geoemoción: hacer del lugar más que una imagen [Mensaje en un blog]. Recuperado de http://goo.gl/W4wzRk

Nogué, J. (6 de mayo de 2009). Geografías emocionales. La vanguardia. Recuperado de http://goo.gl/mLVZWe

Nogué, J. (2009). Entre paisajes. Barcelona: Àmbit.

Nogué, J., \& San Eugenio, J. (2011). La dimensión comunicativa del paisaje. Una propuesta teórica y aplicada. Revista de Geografía Norte Grande, 49, 25-43.

Olsson, G. (1997). Misión imposible. Anales de Geografía de la Universidad Complutense, 17, 39-51.

Ortega-Valcárcel, J. (2000). Los horizontes de la geografía: Teoría de la geografía. Barcelona: Ariel.

Peet, R. (1998). Modern geographical thought. United States: Blackwell Publishing.

Pillet, F. (2004). La geografía y las distintas acepciones del espacio geográfico. Investigacions geográficas, 34, 141-154.

Sack, R. D. (1997). Homo geographicus: A framework for action, awareness and moral concern. Baltimore: Johns Hopkins University Press.
Santis, H., \& Gangas, M. (2004). La aproximación humanística en geografía. Revista de geografia Norte Grande, 31, 31-52.

Silva, A. (1997). Imaginarios urbanos: cultura y comunicación urbana. Bogotá: Tercer Mundo.

Soja, E. (1996). Thirdspace: Journeys to Los Angeles and other real and imagined places. Malden: Blackwell.

Thien, D. (2005). After or beyond feeling? A consideration of affect and emotion in geography. Area, 37(4), 450-454.

Tuan, Y. F. (1976). Humanistic geography. Annals of the Association of American Geographers, 66(2), 266-276.

Tuan, Y. F. (1977). Space and Place. The perspective of experience. London: Arnold.

Unwin, T. (1995). El lugar de la geografia. Madrid: Cátedra.

Urry, J. (2005). The Place of emotions within place. En J., Davidson, L., Bondi \& M. Smith (Eds). Emotional Geographies (pp.77-83). Aldershot: Ashgate. 